\title{
Pulmonary Thromboembolism in COVID-19: Proposal for a Scoring System for Diagnosis
}

\author{
Alberto Saraiva Tibúrcio, $M D^{1^{*}}$ and Fabíola Curvello Leite Tibúrcio, MD \\ ${ }^{1}$ Infectious Diseases Physician, Master in Health Sciences at Universidade Federal Fluminense, Brazil \\ ${ }^{2}$ Dermatology Specialist by the Brazilian Society of Dermatology, Brazil
}

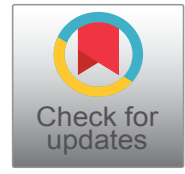

*Corresponding author: Alberto Saraiva Tibúrcio, MD, Infectious Diseases Physician, Master in Health Sciences at Universidade Federal Fluminense, Rua Rodrigo da Silva Pimenta Martins Filho, 48. Morada da Colina, Resende-RJ CEP: 27523-336, Brazil

\begin{abstract}
Background: Pulmonary thromboembolism is a clinical condition that is difficult to diagnose and highly lethal if not diagnosed and treated in time. The COVID-19 pandemic has greatly increased the incidence of PTE in patients affected by the SARS-CoV-2 virus.
\end{abstract}

Methods: A score system was built based on the frequency of signs and symptoms presented in the literature on pulmonary thromboembolism.

Results: Tachypnea $(+12)$, chest pain $(+12)$, dyspnea $(+11)$, pleuritic pain $(+10)$, seizure $(+8)$, P2 hyperphonesis $(+7)$, cough $(+7)$, tachycardia $(+6)$, fever $(+6)$, sweating $(+5)$, phlebitis $(+5)$, hemoptysis $(+4)$, cyanosis $(+4)$, syncope $(+3)$ constitute the score for a very likely diagnosis $(68-100$ points), probable (34-67 points) or unlikely (0-33 points) of pulmonary thromboembolism.

Conclusion: The proposed scoring system can help in the diagnosis of pulmonary thromboembolism in patients with COVID-19 treated at an emergency care unit.

\section{Keywords}

COVID-19, Pulmonary thromboembolism, Diagnosis, Scoring system

\section{Introduction}

On July 16,2020 , at the time of making this manuscript, the COVID-19 pandemic, a disease caused by the new coronavirus SARS-CoV-2, has already reached more than 13.7 million confirmed cases on a global scale and about six thousand deaths daily, totaling more than 587 thousand deaths [1]. This pandemic, in turn, has brought in its wake an increase in the incidence of thromboem- bolic phenomena, of which one of the most important is pulmonary thromboembolism (PTE), the focus of this brief communication. As an introduction to the subject, two important studies should be highlighted.

The first of these studies demonstrated an increase in the incidence of PTE by comparing 107 patients with COVID-19 and 196 patients without COVID-19 admitted to an intensive care unit (ICU) from February 27 to March 31, 2020. The incidence of PTE in both groups was $20.6 \%$ and $6.1 \%$, respectively. Another comparison of the study, this time with 40 Influenza patients also admitted to this ICU from January 1 to December 30,2019 , showed that the incidence of PTE in this last group was $7.5 \%$ [2].

The second of these studies, based on a series of seven autopsies, showed the presence of platelet-rich thrombosis in the pulmonary, hepatic, renal and cardiac microvasculature. Megakaryocytes containing viral particles were found in an increased number in the bone marrow and also deposited in the thrombi of the microvasculature, indicating a participation of these cells in multiple organ failure [3].

Several factors can contribute to the development of a state of hypercoagulability in patients with COVID-19: The development of the cascade of inflammatory mediators, pulmonary and peripheral endothelial lesions resulting from a direct viral attack, and an aggressive immune response [4]. This hypercoagulability is evidenced by a prolonged prothrombin time, high levels of D-dimer, fibrinogen and fibrin degradation products, and a

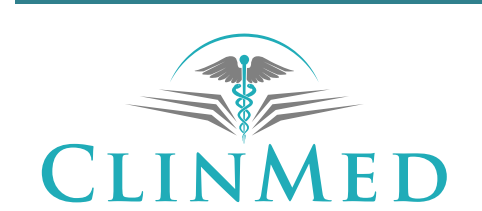

INTERNATIONAL LIBRARY

Citation: Tibúrcio AS, Tibúrcio FCL (2020) Pulmonary Thromboembolism in COVID-19: Proposal for a Scoring System for Diagnosis. Int J Clin Biostat Biom 6:029. doi.org/10.23937/2469-5831/1510029 Received: July 17, 2020: Accepted: August 24, 2020: Published: August 26, 2020

Copyright: (C) 2020 Tibúrcio AS, et al. This is an open-access article distributed under the terms of the Creative Commons Attribution License, which permits unrestricted use, distribution, and reproduction in any medium, provided the original author and source are credited. 


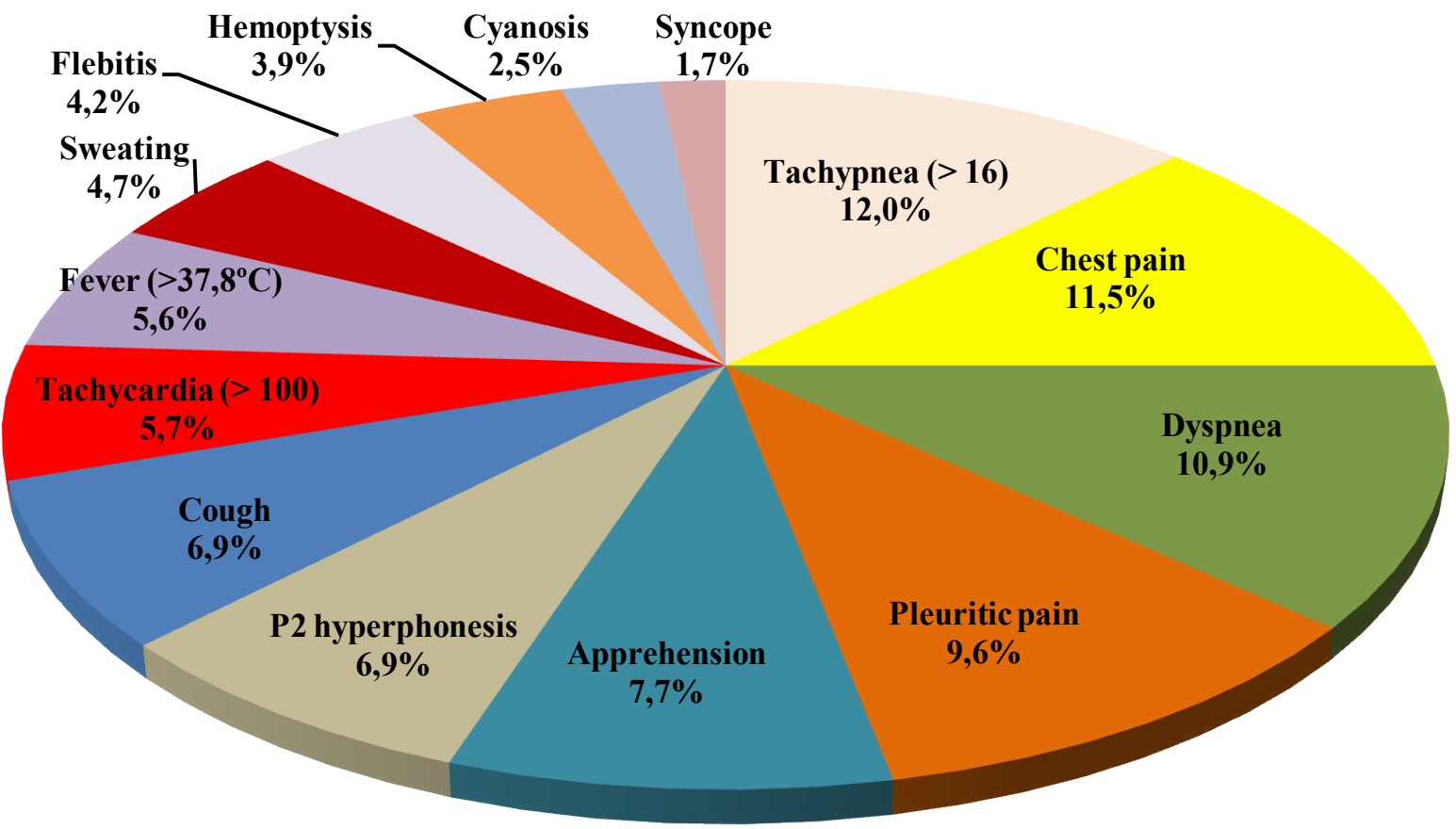

Figure 1: Signs and symptoms of 100 patients with acute PTE $(n=768)$.

partial thromboplastin time close to normal. Levels of Interleukin-6, a cytokine that activates the coagulation system and inhibits the fibrinolytic system, are elevated $[4,5]$.

In view of the evidence that PTE participates significantly in the pathophysiology of COVID-19, contributing to the high lethality of this disease, it is important to recognize this condition early and quickly install the treatment. However, it is worth remembering that the clinical diagnosis of PTE has always been challenging, even before the COVID-19 pandemic.

Currently, in the presence of a confirmed or even suspected case of COVID-19, it is often necessary to use more sophisticated complementary tests, such as echocardiography and computed angiotomography, for the diagnosis of PTE. The echocardiogram may show signs of overload and dysfunction of the right ventricle, while an angiotomography should be reserved for cases with high suspicion of PTE and negative echocardiography, due to the possibility of developing contrast-induced nephropathy [5]. However, these complementary exams are only performed inside hospitals, and are not available in emergency care units.

PTE is a clinical syndrome resulting from the presence of emboli or thrombi formed in situ, occluding pulmonary arterial circulation $[3,6]$. The clinical picture is variable and depends on the patient's previous cardiopulmonary conditions, the number and size of the emboli or thrombi, and the patient's neurohumoral response $[3,6]$.

\section{Methods}

Based on a list of the main signs and symptoms of acute PTE [6], a scoring system was arbitrarily constructed through which the probability of a case of PTE can be measured as 'unlikely', 'likely' or 'very likely'.

The frequencies of signs and symptoms of acute PTE presented by Póvoa [6] are as follows: Tachypnea $>16$ $(92 \%)$, chest pain (88\%), dyspnea (84\%), pleuritic pain (74\%), seizure (59\%), P2 hyperphonesis (53\%), cough (53\%), tachycardia > $100(44 \%)$, fever $>37.8^{\circ} \mathrm{C}(43 \%)$, sweating (36\%), phlebitis (32\%), hemoptysis $(30 \%)$, cyanosis (19\%), and syncope (13\%) [6]. As the frequency data are presented in percentages of patients [6], a hypothetical case series of 100 patients was adopted. The frequencies of signs and symptoms were then added as if they were frequencies in absolute numbers, resulting in 768. This total of signs and symptoms corresponds, then, to $100 \%$ of the sum of all frequencies, as shown in Figure 1.

Finally, each percentage of the graph was transformed into number of points, making a total of 100 points. An 'unlikely diagnosis of PTE' would be between 0-33, 'likely diagnosis' between 34-67 and 'very likely diagnosis' between $68-100$ points.

\section{Results}

As the probability scale ranges from 0 to $100 \%$, each percentage of the graph has been transformed into a number of points. Thus, we have:

\begin{tabular}{|l|l|}
\hline & Score \\
\hline Tachypnea $(>16)$ & +12 \\
\hline Chest pain & +12 \\
\hline Dyspnea & +11 \\
\hline Pleuritic pain & +10 \\
\hline
\end{tabular}




\begin{tabular}{|l|l|}
\hline Apprehension & +8 \\
\hline P2 hyperphonic & +7 \\
\hline Cough & +7 \\
\hline Tachycardia $(>100)$ & +6 \\
\hline Fever $\left(>37.8^{\circ} \mathrm{C}\right)$ & +6 \\
\hline Sweating & +5 \\
\hline Phlebitis & +5 \\
\hline Hemoptysis & +4 \\
\hline Cyanosis & +4 \\
\hline Syncope & +3 \\
\hline
\end{tabular}

\section{Discussion}

A scoring system is useful only when it really adds value to a diagnosis, or when it can replace a more sophisticated procedure that is not currently available [7]. Thinking about the difficulties encountered in making a difficult diagnosis like PTE, in a scenario of emergency care, the author of this work is proposing the use of a scoring system. In this sense, the scoring system can serve as a way of screening patients with suspected PTE in patients with confirmed or even suspected COVID-19.

The signs and symptoms of PTE were initially expressed as percentages, which are considered continuous variables. The conversion of each percentage into a numerical score was done in two steps. The first step consisted of considering a sample of 100 patients, in which all signs and symptoms could be added together as absolute numbers. In the second step, the result of this sum (768) was the new denominator by which each absolute number was divided. The sum of all these divisions by 768 was $100 \%$. As the scoring system varies from 0 to +100 , the conversion of the percentages found in the second step to scores was done automatically. This methodology, contrary to the literature, was not a difficult challenge to be overcome [7].

The arbitrary division into three levels of probability for the diagnosis of PTE, as done in the construction of the score system presented here, is not new. There are examples of scoring systems where the assessment of the possibility of a diagnosis was constructed in an arbitrary manner and the results found had a good correlation with the clinical findings [7].

The use of scores for qualitative variables, such as signs and symptoms, requires compliance with certain requirements, such as validity and reliability. The validity concerns the consistency and reproducibility of the results found, as well as the possibility of comparison with other systems already in use. The reliability of a scoring system, in turn, is related to the interpretation of instructions by the evaluators and by the patients being evaluated [7].

This study sought to focus on a methodology for building a scoring system that can help in the diagnosis of PTE in patients with COVID-19. This scoring system presented here still needs to be evaluated for its validity and reliability.

\section{Conclusion}

The COVID-19 pandemic has contributed significantly to the increase in the incidence of PTE, a condition that is often fatal if not diagnosed and treated in time. In this context, the use of a scoring system to help make a diagnosis of PTE can be a very useful tool for the physician who attends an emergency care unit, where there are generally not many resources in terms of complementary exams.

\section{References}

1. COVID19INFO.LIVE.

2. Poissy J, Goutay J, Caplan M, Parmentier E, Duburcq T, et al. (2020) Pulmonary embolism in patients with COVID-19: Awareness of an increased prevalence. Circulation 142: 184-186.

3. Rapkiewicz AV, Mai X, Carsons SE, Pittaluga S, Kleiner DE, et al. (2020) Megakaryocytes and platelet-fibrin thrombi characterize multi-organ thrombosis at autopsy in COVID-19: A case series. EClinicalMedicine 24: 100434.

4. Cao W, Li Taisheng (2020) COVID-19: Towards understanding of pathogenesis. Cell Res 30: 367-369.

5. Rouhezamin MR, Haseli S (2020) Diagnosing pulmonary thromboembolism in COVID-19: A stepwise clinical and imaging approach. Acad Radiol 27: 896-897.

6. Póvoa R (1996) Pulmonary thromboembolism: Clinical picture and diagnosis. Arq Bras Cardiol 67: 197-199.

7. MedicalBiostatistics.com. Medical scoring. 